\title{
Portable embedded system for the measurement of a vertical high jump
}

\author{
Adrián Castañeda ${ }^{1}$, Axel Elías ${ }^{2}$, and David Elías ${ }^{3}$ \\ 1 UPIITA - IPN, Electronics Department \\ D.F., MX, 5729-6000 ext. 56882 \\ acastanedag@ipn.mx \\ http://www. upiita.ipn.mx \\ 2 Instituto de Investigaciones Dr. José María Luis Mora \\ D.F., MX, 5598-3777 \\ aelias@iijlmora.mx \\ http://www. www. mora.edu.mx \\ 3 Centro de Investigación y de Estudios Avanzados del IPN \\ D.F., MX, 5747-3800 \\ delias@cinvestav.mx \\ http://http://www. cinvestav.mx/
}

\begin{abstract}
In this article we launch a low cost design of an embedded portable system to measure the height of a vertical jump through contact platforms. The "SALTOMETRO", name given to the embedded system, can measure up to $32 \mathrm{~s}$ of flight time with a resolution of $500 \mu \mathrm{s}$, can calculate the vertical jump height and show it in a liquid crystal display (LCD) in less than 2s. "SALTOMETRO" consists of a microcontroller that operates in a $1 \mathrm{MHz}$ frequency, a LCD, a Li-Ion battery, a conditioning signal stage for passive or active circuits whit normally open (NO) or normally closed (NC) switches or signals and can use any type of contact platform, either commercial or made in laboratory does not require of a computer for its operation and the lithium ion battery (Li-Ion)of $1200 \mathrm{~mA} / \mathrm{h}$ can last up to one week without recharge with an approximate use of 3 hours per day. The cost of construction is below $\$ 35$ dollars.
\end{abstract}

Keywords: embedded system, vertical jump, contact platform

\section{Introduction}

To evaluate the anaerobic power there are several of tests. These have been classified into direct and indirect, as well as of field and of laboratory [1].Measuring the height of a vertical jump is an indirect methodology applied in the laboratory, while in field, there are a great amount of studies that evaluate the effects of different training programs [2]; there are also studies that compare the leaps of athletes of different sports [3], or studies that appraise different level of performance in one kind of sport $[4,5]$, and some that relate the physical condition 
with health $[6,7]$.

The three basic methodologies to measure the height of the vertical jump [8, 9] are:

Numerical integration: Considered as the direct or reference method, it obtains the height of the leap, by the use of strength platforms.

Mark differentiation: It makes use of non-standardized mechanisms to realize marks with parts of the body, making it difficult to compare the results between different tests that use this methodology because they depend of the part of the body that is marked [10].

Time of flight: It requires the use of mechanical contact platforms [11] or optoelectronic ones [2].

The time of flight and the mark differentiation are the most utilized laboratory and field methods because these require simpler, cheaper and easy to acquire material $[10,12]$. The main advantage of time of flight over the mark differentiation is that it gives a more objective measure of the height of the leap [10], in addition, it is a more valid and reliable procedure [12] and its use is part of the many scientific methodology studies [2,7,13-25]; although, various works have evidenced that this method systematically registers more height of leap than the one acquired by numerical integration because of the extension in the landing that the angles of the ankle, knee and hip present [26-28].

In the market, we can find opto-electronic systems parallel to the ground to measure the time of flight such as Photocell Contact Mat, the Jump Bosco Infrared System [29] and the SportJump System Pro [8]. Contact platform systems such asthe Ergo Jump Bosco/System [30], the Tapewitch Signal Mat, Model CVP 1723 (Mijares and colaborators., 1995); DIGITIME 1000 [31] and the CHRONOJUMP Boscosystem. All the systems, except for DIGITIME 1000, Tapewitch Signal Mat and Ergo Jump Bosco System require a computer to measure and capture the time and have not been validated, with the exception of Photocell Contact Mat and CHRONOJUMP Boscosystem [9].

The study of anaerobic power by the test that measures the height of the leap has proven to be the most used methodology by the scientific community, but there is a small variety of equipment to measure it. Their difficult accessibility, cost, validation and portability, has made the data difficult to compare with their homologous around the world, shortening the possible impact that these could have as a collective knowledge; this is why, the objective of this work is to design an embedded portable system for the measurement of the height of the vertical jump using the methodology of flight time through a contact platform that does not require a computer for its functioning; that it would be easy to make with a low cost; that can use the contact and optics platforms from different commercial or own systems; that it would also be validated and certified by calibrated equipment, achieving a better level of certainty and confidence in 
the measures realized; and finally, that the time that contact platforms underestimate will become a constant that can be eliminated out of the equation so researchers in all over the world can compare the obtained results.

\section{Meterials and Methods}

\subsection{Mathematical aspects}

In a high jump, the behavior of the gravity center of a person works as a projectile thrown with determined angle, or in the best case scenario as a vertical shaft. The elevation of the gravity center of the test subject corresponds to the height of the jump, which depends on the vertical speed of the takeoff $V_{0}$; in other words, $H_{\max }=V_{0}^{2} / 2 g$. See Fig. 1 .

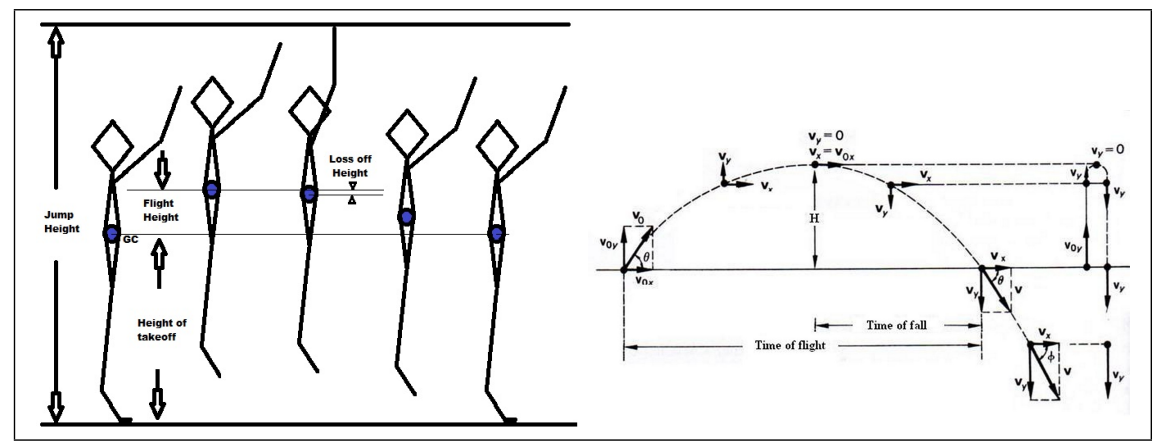

Fig. 1. High jump and its description as a parabolic throw

To simplify the calculation, the computational cost and to achieve that the device does not have accelerometers or force platforms, we can see that when the center of mass arrives to the maximum height, its velocity is equal to cero so in that moment it behaves likes a free falling object [33]. Then the vertical movement $H=g * t_{\text {fall }}^{2} / 2$; where $g=981 \mathrm{~cm} / \mathrm{s}^{2}$ and tfall is the time from the maximum height until it touches the ground (time of fall). If we measure the time of flight that is the double of the time of fall, then the calculation of the maximum height reduces to:

$$
H_{\max }=122.6 * t_{\text {flight }}^{2}(\mathrm{~cm})
$$

\subsection{Development of the system's hardware}

The first stage of the SALTOMETRO is the conditioning of signals of active, passive, normally open (NO) or normally close (NC) sensors. Most of the sensors 
in the market have plug stereo connectors or RCA, but in this case a jack stereo connection was used because of its size, making this a design parameter. After the entry there is a DPDT switch (Sw1), which is connected to an opto-coupler TLP521-1 (IC1) through a diode (D1). The objective of IC1 is adapting the signal that comes from the sensor, independently if it's active, passive, NO or NC and it does not provide protection or isolation of voltage to the microcontroller ATTINY2313 (IC2) because the sources of voltage are the same ones.

The Sw1 switch selects if the type of sensor is NO or NC (please note the form of activating the opto-coupler) while the diode D1 works to avoid that the active sensors inject the current to light up the led and send false alarms. In the transistor's collector output of IC1 there is a resistance of $15 k \Omega$ next to a $\mathrm{C} 1$ capacitor to land of $10 \mu \mathrm{F}$ to form a down pass filter of $150 \mathrm{~ms}$ time charge to avoid noise from the hardware into the measurement of jumps below $2.76 \mathrm{~cm}$. Once the signal is filtered, it is sent to the microcontroller (IC2) in a pin for monitoring external interruptions (PD2) and the processing of the measurement is sent to a LCD device to show an alphanumerical result. Finally, a pulse button (Sw2) is placed to start a new measurement when the operator requires it. Observe the Fig. 2

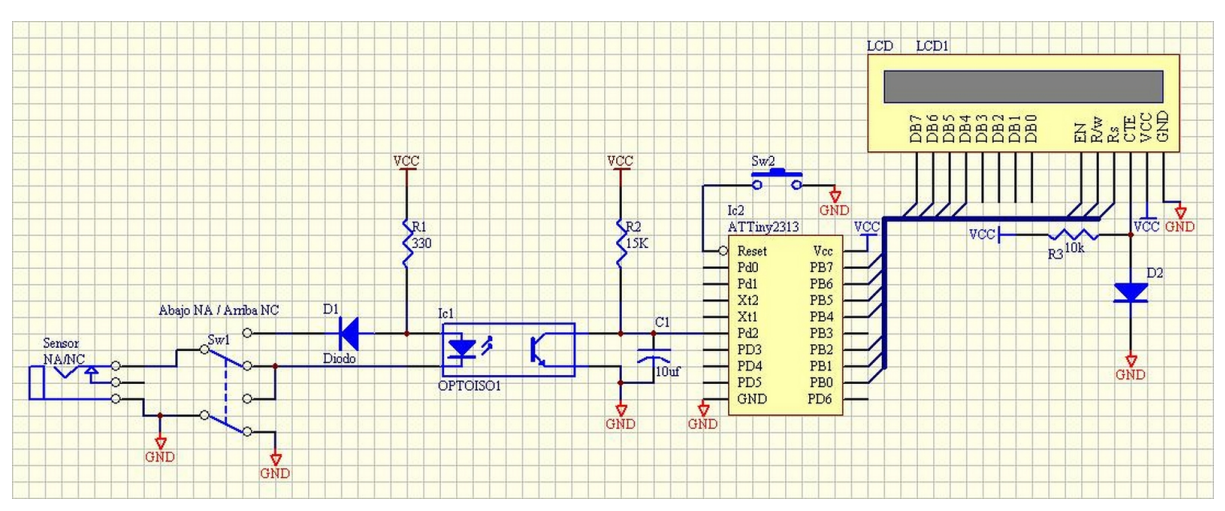

Fig. 2. Schematics of the SALTOMETRO

\subsection{Development of the system's software}

The SALTOMETRO software is coded in $\mathrm{C}$ language and is divided in the following subprograms: Main, Monitor and timer. The "Main subprogram" is in charge of configuring the microcontroller with the side of the interruption pin in flank of ascent and the timer countdown each $500 \mu \mathrm{s}$, as well as, initiating the variables of control, height and time. Once the machine is configured, the 
microcontroller will wait for the timer and interruption events. The Monitor routine is in charge of verifying the interruption pin to know if the person is located on the platform or in flight; stopping the TIMER routine; calculating the height of the jump and showing the result in the LCD. Finally, the Timer function is in charge of counting the machine cycles, generating interruptions each $500 \mu s$. Observe the Fig. 3 of the flowchart.

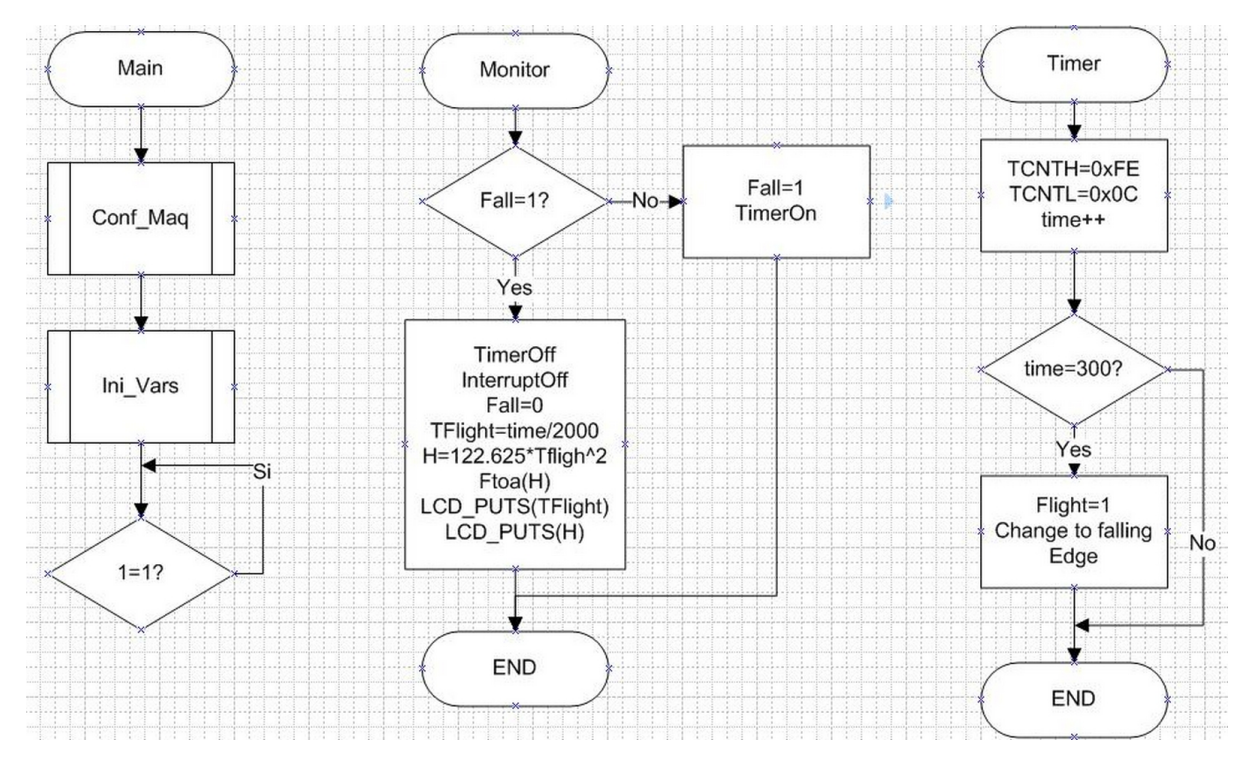

Fig. 3. Flowshart of SALTOMETRO

The logic of the program is based on the following execution sequence:

1. Ask the test subject to stand over the platform

2. Turn on the SALTOMETRO or press Reset (Sw2)

3. Configure microcontroller

4. Initiate Variables

5. Ask the test subject to execute the jump

6. Monitoring the platform for the takeoff event

7. Initiate timer

8. After $150 \mathrm{~ms}$, change monitoring of platform in the descent

9. In the moment test subject and platform make contact
(a) Stop the timer
(b) Stop interruptions
(c) Calculate the height of jump
(d) Show result

10. Record the result

11. Repeat step 1 for another measurement. 


\subsection{Instruments}

Contact platform A contact platform with metallic strips was used and assembled with gymnasium wooden floor so it could soften the fall after the jump. The contact detection area is $0.90 \mathrm{~m}^{2}$ and the method of detection is by aperture and/or closure of the metallic strips while the contact of feet occurs. The methodology used for the construction of the contact platform is that recommended by CHRONOJUMP Boscosystem [32].

Osciloscope We used a digital Tektronix color oscilloscope, model TS20146, of 4 channels, $100 \mathrm{MHz}, 1 \mathrm{GS} / \mathrm{s}$ bandwidth, memory of $2.5 \mathrm{kpts}$, mathematical functions (including FFT), advanced triggers, transference of data and 1GS USB storage.

Digital signal generator In this case, a Tektronix digital signal generator, model AFG3101, was used. The generator can create standard and arbitrary programmed functions; it has one channel with a rank from $1 \mathrm{MHz}$ to 100 $\mathrm{MHz}, 1 \mathrm{Gs} / \mathrm{s}$, 14-Bit resolution, AM/ FM/ PM/ FSK/ PWM modulations, GPIB, USB, LAN and color screen.

\subsection{Experimental design}

The experiment consists of 2 phases:

1. The objective of the first phrase is to determine the linearity, exactitude and precision of the device in an interval from $200 \mathrm{~ms}$ to $1500 \mathrm{~ms}$ that corresponds to the jumps of heights from $4.9 \mathrm{~cm}$ to $278.85 \mathrm{~cm}$. To achieve this, the AFG3101 digital signal generator is programmed with a squared signal of $5 \mathrm{v}$ amplitude and a variable width of pulse in the proposed rank; the sequence is repeated 10 times and the calculations of height and times are registered by the SALTOMETRO; meanwhile, with the TS2014B oscilloscope, which is connected in a parallel with the device and the signal generator, we register each event and verify the width of pulse and the type of wave delivered by AFG3101.

2. The second phase has the objective of observing the signal of response of the contact of platform when connected to the SALTOMETRO, if it has rebounds, added delays by the coupling stage, and in consequence, the device's errors while measuring the time of flight and calculating the height of the jump. For this, the contact platform is connected to the SALTOMETRO in parallel with the TS2014B oscilloscope, the execution sequence is made and every event is registered.

\section{Results}

Ten events were registered in each interval for the filling of table 1 , as explained next. In the first column, we can find the time of flight in ms generated artificially by the AFG3101 signal generator. The second column shows the average in ms of the 10 events in each registered interval and shown by the SALTOMETRO. 
In the third column, the standard deviation of the previous column is shown. The fourth column shows the calculations of the real height due to the times of flight generated in column 1 . In the fifth column, the average of time calculated by the SALTOMETRO with only one decimal digit is shown. Finally, in column 6 , the magnitude of error due to the difference between the real height and the average of calculated heights is shown by the SALTOMETRO.

Table 1. Results of experimental design, phase 1

\begin{tabular}{cccccc}
\hline TV(ms) & Mean TV(ms) & $\sigma(m s)$ & H Real $(\mathbf{c m})$ & H Calc(cm) & ERROR(cm) \\
\hline 200 & 199.9 & 0.459468292 & 4.904 & 4.9 & 0.0040 \\
\hline 300 & 300.1 & 0.459468292 & 11.034 & 11.0 & 0.0340 \\
\hline 400 & 400 & 0.471404521 & 19.616 & 19.6 & 0.0160 \\
\hline 500 & 500 & 0.40824829 & 30.65 & 30.7 & 0.0500 \\
\hline 600 & 600 & 0.333333333 & 44.136 & 44.1 & 0.0360 \\
\hline 700 & 700.1 & 0.516397779 & 60.074 & 60.1 & 0.0260 \\
\hline 800 & 800 & 0.471404521 & 78.464 & 78.5 & 0.0360 \\
\hline 900 & 900.05 & 0.368932394 & 99.306 & 99.3 & 0.0060 \\
\hline 1000 & 1000 & 0.527046277 & 122.6 & 122.6 & 0.0000 \\
\hline 1100 & 1100.05 & 0.437797518 & 148.346 & 148.4 & 0.0540 \\
\hline 1200 & 1200.15 & 0.474341649 & 176.544 & 176.5 & 0.0440 \\
\hline 1300 & 1299.95 & 0.368932394 & 207.194 & 207.2 & 0.0060 \\
\hline 1400 & 1400.05 & 0.368932394 & 240.296 & 240.3 & 0.0040 \\
\hline 1500 & 1499.95 & 0.368932394 & 275.85 & 275.8 & 0.0500 \\
\hline- & - & - & - & - & - \\
\hline- & Average $\sigma$ & $\mathbf{0 . 4 3 1 0 4 5 7 2}$ & - & Average error & $\mathbf{0 . 0 2 6 1}$ \\
\hline
\end{tabular}

To know in detail the characteristics of precision, exactitude and linearity of the device, the measurements of central tendency and deviation or separation of the data related to their arithmetic average are shown. In table 1 we can observe that the average of standard deviation of time of flight in all the rank of measurements is $0.431 \mathrm{~ms}$ and that the error average in the calculation of the height is barely $0.0261 \mathrm{~cm}$. Fig. 4 shows the correlation of the registered data with the generated ones and the tendency line in all the rank of time.

Figure 5 shows the SALTOMETRO device and its two contact platforms made with floor for gym.

\section{Discusion}

In this research we present the design of a portable embedded system for the measurement of the high jump with the flight time methodology through contact platforms with a stage of signal conditioning that allows the use of contact platforms and optics from different commercial systems and can be built by people with few electronic abilities and with an approximate cost of $\$ 35$ US dollars. The system shows linearity in the rank between $200 \mathrm{~ms}$ and $1500 \mathrm{~ms}$ and shows equivalency to an interval of heights from $4.9 \mathrm{~cm}$ to $275.85 \mathrm{~cm}$. The obtained results show that the device is exact, precise and linear with an average standard deviation of $0.431 \mathrm{~ms}$ for the time of flight and an average error in the 


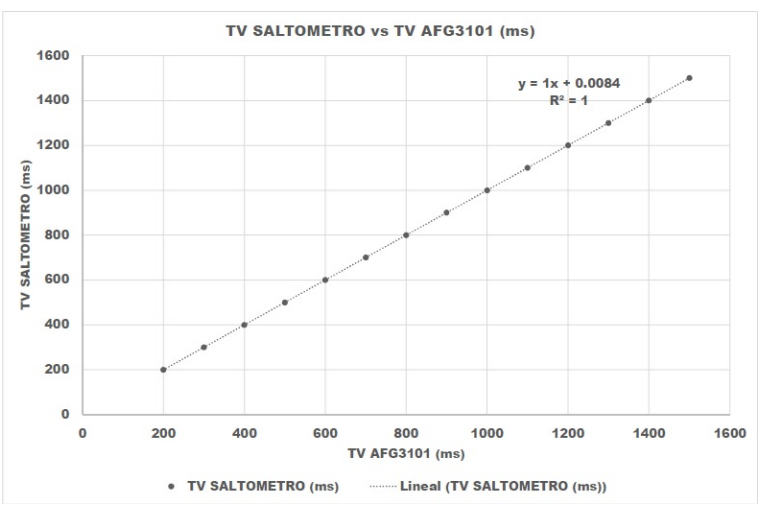

Fig. 4. Response of SALTOMETRO in all the rank of time

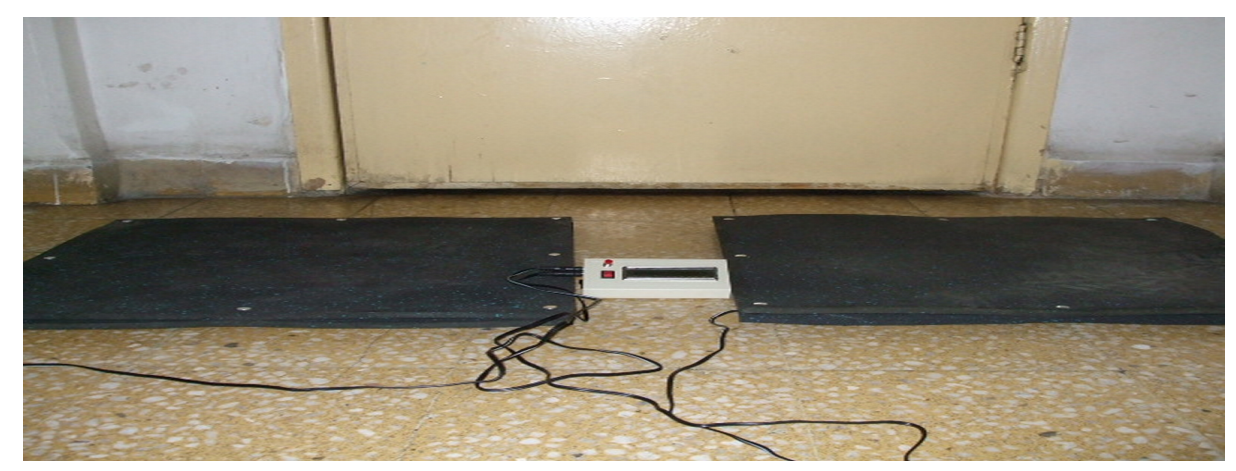

Fig. 5. SALTOMETRO and contact platforms 
calculation of height of $261 \mu \mathrm{m}$ due to the round out to one decimal number. The SALTOMETRO is not the best device that is offered in the marked because it does not offer connection of any type to a computer; nevertheless, some of its best stand out qualities are: the size and its portability $(11 \times 7 x 2.5 \mathrm{~cm}$ and $60 \mathrm{~g})$; its battery lifetime, low cost, and its automatic calculation and visualization of the flight height in LCD. In addition, with the performed researches made with certified equipment, linearity, exactitude, precision and recurrence of the device can be guaranteed; people that use this device will be able to compare their results with certainty because the errors or discrepancies will be due only to the method and not the equipment.

\section{Acknowledgments}

The authors thank the support from CONACYT, UPIITA-IPN, CINVESTAV and CONADE for carrying out this work.

\section{References}

1. RODRGUEZ, F.A., ARAGONS, M.T.: Valoracin funcional de la capacidad de rendimiento fsico. , Ed. Interamericana McGraw-Hill, Madrid, (1992).

2. IMPELLIZZERI, F.M., RAMPININI, E., CASTAGNA, C., MARTINO, F., FIORINI, S. and WISLOFF, U.: Effect of plyometric training on sand versus grass on muscle sorenessand jumping and sprinting ability in soccer players. British Journal of Sports Medicine 42, 42-46 (2008).

3. SLEIVERT, G., BACKUS, R. and WENGER, H.: Neuromuscular differences between volleyball players, middle distance runners and untrained controls. International Journal of Sports Medicine 16 (6), 390-398 (1995).

4. COMetTi, G., MAffiuletti, N.A., POUsson, M., ChAtARD, J.C. and MAFFULLI, N.: Isokinetic Strength and Anaerobic Power of Elite, Subelite and Amateur FrenchSoccer Players. International Journal of Sports Medicine 22 (1), 45-51 (2001).

5. VAQUERA, A., RODRGUEZ, J.A., VILlA, J.G., GARCA, J. and VILA, C.: Cualidades fisiolgicas y biomecnicas del jugador joven de Liga EBA. Motricidad: EuropeanJournal of Human Movement 9, 43-63 (2002).

6. TABERnERO, B., VILlA, J.G., MRQUEZ, S. and GARCA, J.: Cambios en el nivel de condicin fsica relacionada con la salud en mujeres participantes en un programa municipal de baile aerbico. Apuntes: Educacin Fsica y Deportes 61, 74$79(2000)$.

7. RUIZ, J.R., ORTEGA, F.B., GUTIERREZ, A., MEUSEL, D., SJSTRM, M. and CASTILLO, M.J.: Health-related fitness assessment in childhood and adolescence: a Europeanapproach based on the AVENA, EYHS and HELENA studies. Journal of Public Health 14 (5), 269-277 (2006).

8. GARCA, J., PELETEIRO, J., RODRGUEZ, J.A., MORANTE, J.C. and VILLA J.G.: Validacin biomecnica de un mtodo para estimar la altura de salto a partir del tiempo de vuelo. Archivos de Medicina del Deporte 20 (93), 28-34 (2003).

9. GARCA, J. and PELETEIRO, J.,: Tests de salto vertical (II): Aspectos biomecnicos. RendimientoDeportivo.com, N7, (2004), http://www .rendimientodeportivo. com/N007/Arti032F.htm, [Consulted 01/06/2014] 
10. KLAVORA, P.: Vertical-jump Tests: A Critical Review. Strength and Conditioning Journal 22 (5), 70-75 (2000).

11. GarcA, J., Peleteiro, J., ROdGrguez, J.A., MORAnte, J.C., HeRRERO, J.A. and VILLA, J.G., The validation of a new method that measurescontact and flight times during vertical jump. International Journal of Sports Medicine 26 (4), 294-302 (2005).

12. ARAGN, L.F.: Evaluation of Four Vertical Jump Tests: Methodology,Reliability, Validity, and Accuracy. Measurement in Physical Education and ExerciseScience 4 (4), 215-228 (2000).

13. DAL MONTE, A., FAINA, M. and MIRRI, G.: Fatigue and sport, Functional Neurology 17 (1), 7-10 (2002).

14. MAFFIULETTI, N.A., DUGNANI, S., FOLZ, M., DI PIERNO, E. and MAURO, F.: Effectof combined electrostimulation and plyometric training on vertical jump height. Medicineand Science in Sports and Exercise 34 (10), 1638-1644 (2002).

15. GIRARD, O., VASEUX, D. and MILLET, G.P: Comparison of efficiency of three trainingprograms in tennis players. Science y Sports 20, 45-47 (2005).

16. GIRARD, O., LATTIER, G., MICALLEF, J.P. and MILLET, G.P.: Changes in exercise characteristics, maximal voluntary contraction, and explosive strength during prolongedtennis playing. British Journal of Sports Medicine 40 (6), 521-526 (2006).

17. LAFOrTUNA, C.L., MAFFiUletti, N.A., AGOSTI, F. and SARTORIO, A.: Gendervariations of body composition, muscle strength and power output in morbid obesity. InternationalJournal of Obesity 29 (7), 833-841 (2005).

18. LEHANCE, C., CROISIER, J.L. and BURY, T.: Optojump system efficiency in the assessment of lower limbs explosive strength. Science y Sports 20, 131-135 (2005).

19. TESSitore, A., MeEUSEN, R, CORTIS, C. and CAPRANiCA, L.: Effects of differentrecovery interventions on anaerobic performances following preseason soccer training. Journal of Strength and Conditioning Research 21 (3), 745-750(2007).

20. MARGINSON, V., ROWLANDS, A.V., GLEESON, N.P. and ESTON, R.G.: Comparisonof the symptoms of exercise-induced muscle damage after an initial and repeated boutof plyometric exercise in men and boys. Journal of Applied Physiology 99 (3), 1174-1181 (2005).

21. ARTERO, E.G., ESPAA, V., ORTEGA, F.B., JIMNEZ, D., CARREO, F., RUIZ, J.R., GUTIRREZ, A. and CASTILLO, M.J.: Useof whole-body vibration as a mode of warming up before counter movement jump. Journal of Sports Science and Medicine 6 (4), 574-575 (2007).

22. RAMPININI, E., BISHOP, D., MARCORA, S.M., FERRARI, D., SASSI, R. and IMPELLIZZERI, F.M.: Validity of simple field tests as indicators of matchrelatedphysical performance in top-level professional soccer players. International Journalof Sports Medicine 28 (3), 228-235 (2007).

23. BERTUCCI, W., HOURDE, C., MANOLOVA, A. and VETTORETTI, F.: Mechanicalperformance factors of the bmx acceleration phase in trained riders. Science y Sports 22, 179-181 (2008).

24. BUCHHEIT, M.: Field tests to monitor athletic performance throughout a teamsportseason, Science y Sports 23, 29-31 (2008).

25. SARTORIO, A., AGOSTI, F., DE COL, A., MAZZILli, G., MARAZZI, N., BUSTI, C. GALLI, R. and LAFORTUNA, CL: Muscle strength and power, maximum oxygen consumption, and body composition in middle-aged short-stature adults with childhoodonsetgrowth hormone deficiency. Archives of Medical Research 39 (1), 78-83 (2008). 
26. HATZE, H.: Validity and reliability of methods for testing vertical jumping performance. Journal of Applied Biomechanics 14 (2), 127-140 (1998).

27. KIBELE, A.: Possibilities and limitations in the biomechanical analysis of countermovementjumps: a methodological study. Journal of Applied Biomechanics 14 (1), 105-117 (1998).

28. BACA, A.: A comparison of methods for analyzing drop jump performance. Medicine and Science in Sports and Exercise 31 (3), 437-442 (1999).

29. VIITASALO, J.T, LUHTANEN, P., MONONE, H.V., NORVAPALO, K., PAAVOLAINEN, L., SALONEN, M.: Photocell contact mat: a new instrument to measure contactand flight times in running. Journal of Applied Biomechanics 13 (2), 254-266 (1997).

30. BOSCO, C., LUHTANEN, P., KOMI, P.V.: A simple method for measurement of mechanical power in Jumping. Eur. J. Appl. Physiol 50 (2), 273-282 (1983).

31. Luthanen, P.: Evaluacin fsica de los jugadores de ftbol. Apuntes 21 (82), 99-102 (1984).

32. Bernat, B.: Instrucciones para la construccin de una plataforma de contactos para la medicin de la capacidad de salto/s, (2011),

33. TIPPENS. P.: Fisica Conceptos y Aplicaciones. McGraw-Hill, Mxico (2001).

34. Chronojump Boscosystem, http://chronojump.org/construction_contact_ platform_es.html, [Consulted 14/06/2014]. 